\title{
Successful Weaning Using Noninvasive Positive Pressure Ventilation in a Patient with Status Asthmaticus
}

\author{
Tetsuya UedA, Rollin Tabuena, Hisako Matsumoto, Masaya TAKemura, \\ Akio NiIMI, Kazuo CHIN* and Michiaki Mishima
}

\begin{abstract}
In the treatment of severe asthma attack, acute application of non-invasive positive pressure ventilation is shown to be beneficial in some selected patients, while endotracheal intubation and mechanical ventilation is required in the remaining cases. Management with invasive ventilation in status asthmaticus is often associated with complications such as excessive mucus production and atelectasis, which may lead to prolonged hypoxemia and may increase mortality. We present a case of status asthmaticus who developed refractory atelectasis during invasive mechanical ventilation but had a dramatic resolution as well as successful weaning when non-invasive positive pressure ventilation was instituted.

(Internal Medicine 43: 1060-1062, 2004)
\end{abstract}

Key words: atelectasis, endotracheal intubation, noninvasive positive pressure ventilation, status asthmaticus, weaning, mechanical ventilation

\section{Introduction}

Non-invasive positive pressure ventilation (NPPV) has been one of the major advances in respiratory medicine in the last decade. It is now being used to support those with acute respiratory failure, including severe asthma attack. However, its role in complicated courses of status asthmaticus (SA) remains uncertain. The following case illustrates a patient with SA who developed refractory atelectasis during invasive mechanical ventilation (IMV) but had a successful outcome using NPPV.

\section{Case Report}

A 22-year-old male was referred from another hospital for further management of SA triggered by an upper respiratory tract infection. He had a history of asthma since childhood and was maintained on a short acting $\beta_{2}$-agonist. At the previous hospital, he was intubated and had been placed on IMV. The initial finding of the chest radiograph was only hyperinflation of the lung but the repeat radiograph after 24 hours, showed atelectasis on the right middle lobe. The clinical course was further complicated with Serratia marcescens bacteremia from an infected central venous catheter. Despite the aggressive treatment for asthma and infection, clinical improvement was minimal after 7 days and he was transferred to our institution.

On arrival at our institution, the patient was on sedation and on controlled mode ventilation with a tidal volume $\left(\mathrm{V}_{\mathrm{T}}\right)$ of $8 \mathrm{ml} / \mathrm{kg}$, respiratory rate (RR) of $18 / \mathrm{min}$, blood pressure was 124/64 mmHg, pulse was 92 and body temperature of $37.5^{\circ} \mathrm{C}$. Chest examination showed wheezing in all lung fields. The chest radiograph in our hospital showed progression of atelectasis at the right middle lobe (Fig. 1). Arterial blood gas (ABG) analysis showed $\mathrm{pH} 7.33, \mathrm{PaCO}_{2} 53.8$ $\mathrm{mmHg}$, and $\mathrm{PaO}_{2} 73.7 \mathrm{mmHg}$ with $\mathrm{FiO}_{2}$ of 0.9.

The maximum dose of intravenous corticosteroid, 4th generation cephalosporin, inhalation of $\beta_{2}$-agonist and anticholinergic and removal of the infected catheter gradually improved his condition. However, the atelectasis failed to improve despite the bronchial toileting using a bronchoscope or physiotherapy. He still had wheezing when the sedation was not sufficient. The ventilator was set up on the 12th day after intubation: $\mathrm{V}_{\mathrm{T}} 10 \mathrm{ml} / \mathrm{kg}$ with $4 \mathrm{cmH}_{2} \mathrm{O}$ of positive end expiratory pressure; RR 14/min. ABG showed $\mathrm{pH} 7.52$, $\mathrm{PaCO}_{2} 31.2 \mathrm{mmHg}$, and $\mathrm{PaO}_{2} 79.6 \mathrm{mmHg}$ with $\mathrm{FiO}_{2}$ of 0.7 . On the next day, there was a sudden increase in peak airway pressure to $35 \mathrm{cmH}_{2} \mathrm{O}$ and arterial hypoxemia, which we attributed to a mucus plug in the endotracheal tube as con-

From the Department of Respiratory Medicine and *the Department of Physical Therapeutics, Kyoto University, Kyoto

Received for publication November 28, 2003; Accepted for publication July 6, 2004

Reprint requests should be addressed to Dr. Hisako Matsumoto, the Department of Respiratory Medicine, Kyoto University, Graduate School of Medicine, Sakyo-ku, Kyoto 606-8507 


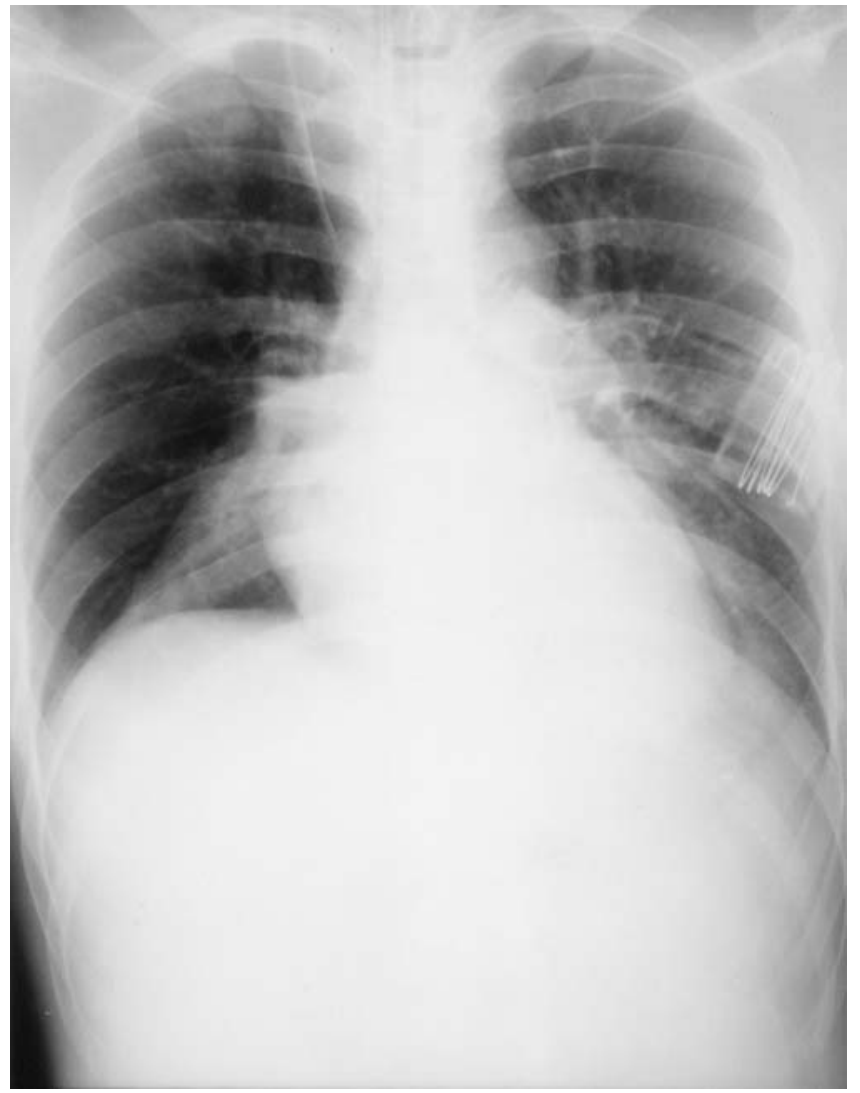

Figure 1. Chest radiograph during the invasive mechanical ventilation, showing atelectasis of the right middle lobe.

firmed by bronchoscopy. The endotracheal tube was extubated and NPPV using full facemask (ResMed, NSW, Australia) was tried carefully. The ventilatory support system used spontaneous with timer backup mode with inspiratory/expiratory pressures of $12 / 5 \mathrm{cmH}_{2} \mathrm{O}$ with 20 liters per minute of oxygen supply, and the peak airway pressure during support ventilation significantly decreased. He tolerated NPPV well and physiological improvement occurred rapidly. ABG immediately after and 24 hours after the institution of NPPV under the same setting showed $\mathrm{pH} 7.46$, $\mathrm{PaCO}_{2} 35.1 \mathrm{mmHg}$, and $\mathrm{PaO}_{2} 62.4 \mathrm{mmHg}$ and $\mathrm{pH} 7.49$, $\mathrm{PaCO}_{2} 30.4 \mathrm{mmHg}$, and $\mathrm{PaO}_{2} 90.7 \mathrm{mmHg}$, respectively. Follow-up radiograph showed a complete resolution of atelectasis (Fig. 2) and thus NPPV was discontinued 72 hours later (Fig. 3). He was ultimately discharged with complete recovery.

\section{Discussion}

To the best of our knowledge, this is the first case report that demonstrates that NPPV could be used as a modality of weaning patients in SA. It can be used safely and applied to the recovery phase of SA complicated by mucus plugging and atelectasis.

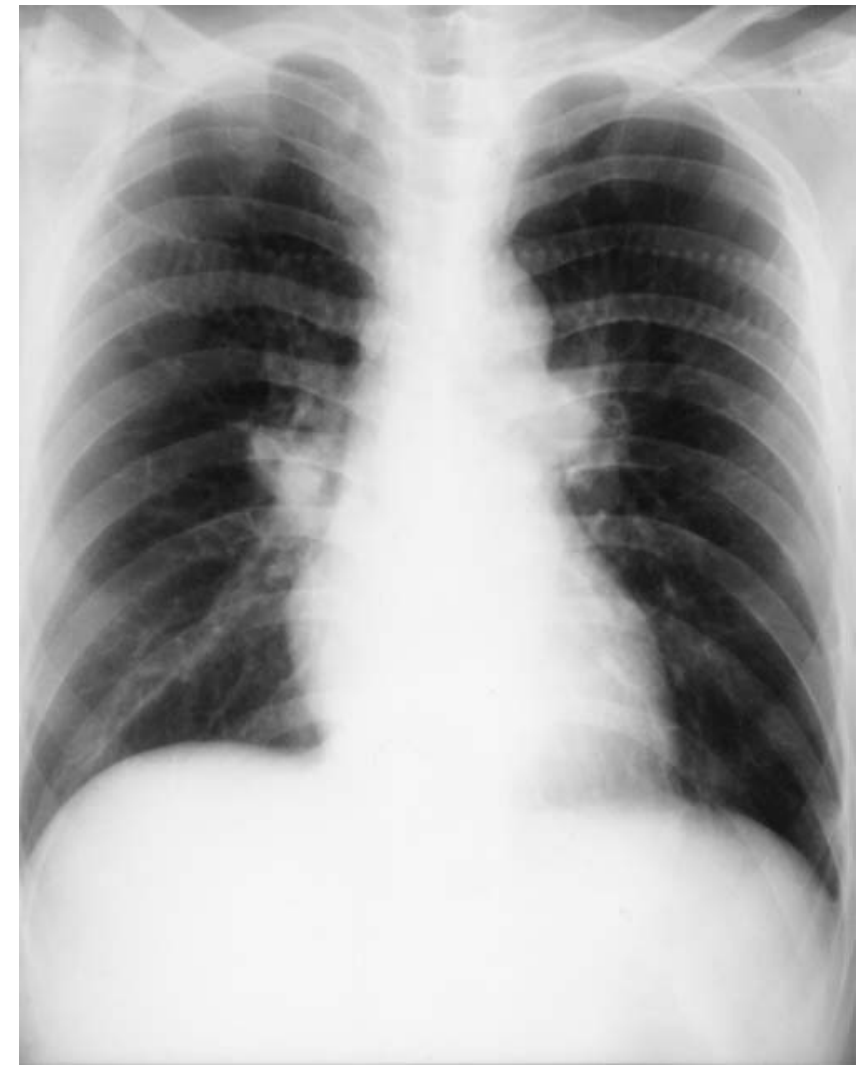

Figure 2. Chest radiograph after 24 hours of institution of noninvasive positive pressure ventilation. Atelectasis was completely resolved.

Refractory atelectasis is one of the causes of the weaning difficulty. During IMV under sedation, the diaphragm shifts toward cephalad direction (1) and this often accompanies atelectasis. Additionally, in this case of SA, endotracheal intubation itself might have further increased the airway resistance (2). These might easily lead to airway closure and atelectasis in the dependent lung zones. Hypersecretion triggered by the irritable tracheal tube (3) and accumulation of mucus due to immobility might also have aggravated the atelectasis.

NPPV has been previously reported as a modality for avoiding IMV in the initial management of SA in selected patients $(2,4-5)$. In this case, the institution of NPPV resulted in successful weaning from IMV. Although the $\mathrm{FiO}_{2}$ requirement was still high at 0.7 , NPPV was applied safely. Removal of the potentially irritating tube might have facilitated the stabilization of the asthma, and decreased airway resistance (2). Spontaneous breathing with bilevel positive airway pressure possibly normalized the diaphragm shift as well as recovered cough reflex, and improved mobility, thereby preventing the stagnation of secretions (2). These factors may act in unison to aid resolution of the collapsed lung. Although the precise mechanisms involved in the resolution of the atelectasis are not yet established, NPPV is 


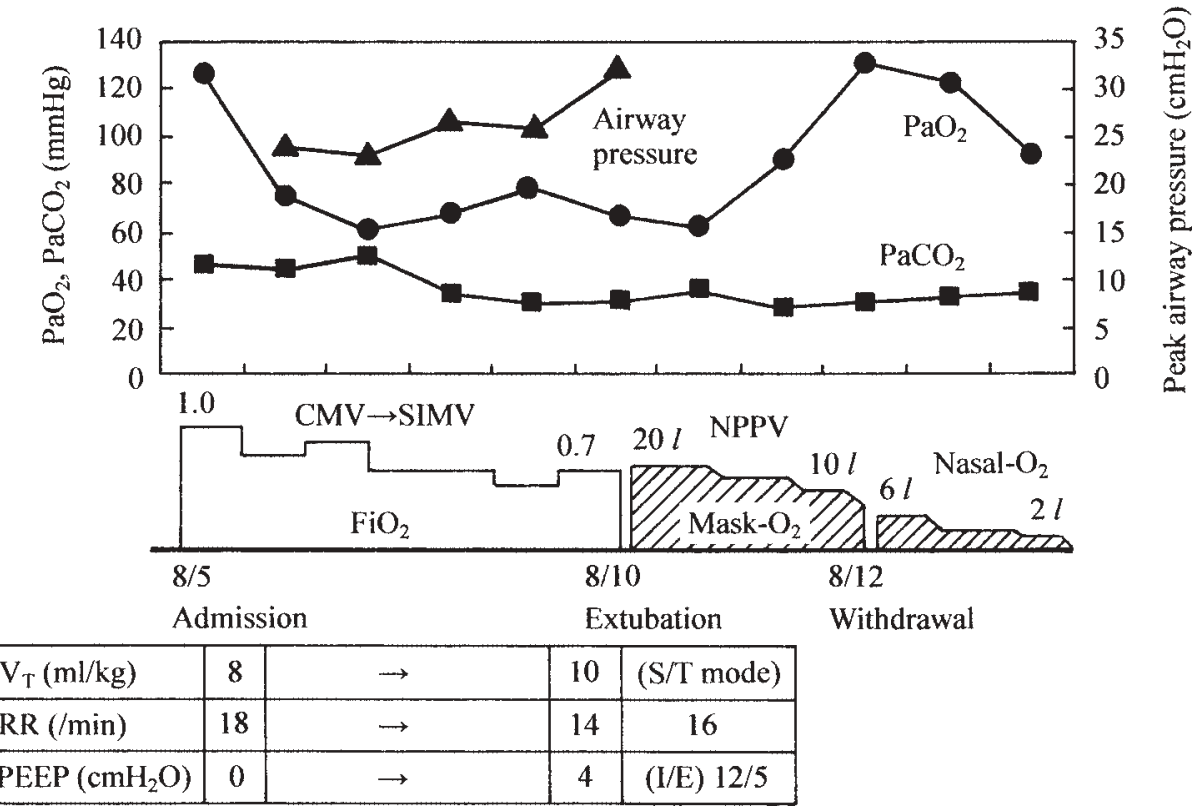

Figure 3. Clinical course.

$\mathrm{PaO}_{2}$ : partial pressure of oxygen in arterial blood, $\mathrm{PaCO}_{2}$ : partial pressure of carbon dioxide in arterial blood, CMV: continuous mandatory ventilation, SIMV: synchronized intermittent mandatory ventilation, NPPV: non-invasive positive pressure ventilation, $\mathrm{FiO}_{2}$ : fraction of inspired oxygen, $V_{\mathrm{T}}$ : tidal volume, $R R$ : respiratory rate, PEEP: positive end expiratory pressure, S/T mode: spontaneous/timed mode, I/E: inspiratory/expiratory ratio.

known to be effective for treating post-operative atelectasis $(6,7)$. In addition, the institution of NPPV may reduce the risk of other potentially fatal complication, such as pneumothorax and ventilator associated pneumonia as reported during the weaning of patients with COPD.

Although NPPV is not established as a routine method for avoiding IMV in SA (5), NPPV appears to be an applicable method for weaning in cases complicated with mucus plugging and refractory atelectasis.

\section{References}

1) Froese AB, Bryan AC. Effects of anesthesia and paralysis on diaphragmatic mechanics in man. Anesthesiology 41: 242-255, 1974.

2) Meduri GU, Cook TR, Turner RE, Cohen M, Leeper KV. Noninvasive positive pressure ventilation in status asthmaticus. Chest 110: $767-774$, 1996.

3) Deem S, Bishop MJ. Physiological consequences of intubation. in: Marini JJ, Slutsky AS, Eds. Physiological Basis of Ventilatory Support. Marcel Dekker Inc., New York, 1998: 623-654.

4) Soroksky A, Stav D, Shpirer I, et al. A pilot prospective, randomized, placebo-controlled trial of bilevel positive airway pressure in acute asthmatic attack. Chest 123: 1018-1025, 2003.

5) Liesching T, Kwok H, Hill NS. Acute applications of noninvasive positive pressure ventilation. Chest 124: 699-713, 2003.

6) Antonelli M, Conti G, Bufi M, et al. Noninvasive ventilation for treatment of acute respiratory failure in patients undergoing solid organ transplantation. A randomized trial. JAMA 283: 235-241, 2000.

7) Meduri GU. Noninvasive positive-pressure ventilation in patients with acute respiratory failure. in: Marini JJ, Slutsky AS, Eds. Physiological Basis of Ventilatory Support. Marcel Dekker Inc., New York, 1998: 921-996. 